\title{
Enfermeiros e saúde pública em Belo Horizonte: combatendo doenças e educando para a saúde (1897-1933)
}

\section{Nurses and Public Health in Belo Horizonte: fighting disease and educating for health (1897-1933)}

\author{
Virgínia Mascarenhas Nascimento Teixeira ${ }^{1}$ \\ Rita de Cássia Marques ${ }^{1}$
}

\begin{abstract}
RESUMO
Este artigo analisa a organização da enfermagem na cidade de Belo Horizonte entre 1897 e 1933 - período anterior à institucionalização desse campo de saber através da criação da Escola de Enfermagem Carlos Chagas. Neste período, as ações de saúde pública estiveram principalmente voltadas ao combate e controle de epidemias e endemias e para a higiene e educação sanitária da população. Entre fins do século XIX até a década de 1910, as ações de saúde tinham na doença seu eixo de orientação e os enfermeiros realizavam atividades em hospitais de isolamento, lazaretos, hospedarias e em domicílios, sob a orientação e o acompanhamento dos médicos, ou informalmente, sem qualquer supervisão, como forma de ajuda ao próximo. As décadas de 1920 e 1930 marcam uma fase de transformações na saúde pública, com ênfase para a prevenção e a educação sanitária. A partir de então, verifica-se a organização de duas frentes de atuação de enfermeiras na prevenção e promoção da saúde: as "enfermeiras visitadoras" e as "enfermeiras escolares", cuja atividade se pautou nas orientações e práticas defendidas pelo pensamento sanitário da época. O presente estudo revela um universo em torno dos enfermeiros ainda pouco trabalhado no contexto da história da enfermagem, principalmente, no que diz respeito a essa história em Minas Gerais, com destaque à capital Belo Horizonte.

Palavras-chave: enfermagem; história da enfermagem; saúde pública; Belo Horizonte.
\end{abstract}

DOI: $10.1590 / 0104-4060.38201$

1 Universidade Federal de Minas Gerais. Curso de Especialização em Formação Pedagógica para Profissionais de Saúde e Escola de Enfermagem. Belo Horizonte, Minas Gerais, Brasil. Av. Alfredo Balena, n. ${ }^{\circ}$ 190. CEP: $30130-100$. 


\begin{abstract}
This article analyzes the organization of nursing in the city of Belo Horizonte between 1897 and 1933 - before the institutionalization of this knowledge field through the creation of the Carlos Chagas Nursing School. At this time, public health actions were mainly geared towards combating and controlling epidemic and endemic diseases and for hygiene and health education of the population. Between the late nineteenth century until the 1910s, health actions had diseases as their axis, and the nurses carried out the activities in isolation hospitals, leper hospitals, hostels and homes under the guidance and monitoring of doctors, or informally and unsupervised as a way of helping others. The 1920s and 1930s marked a period of transformation in public health, with emphasis on prevention and sanitary education. Since then the organization of two fronts of nurses in prevention and health promotion has been observed: the "visiting nurses" and the "school nurses", whose work was based on guidelines and practices advocated by contemporary health education. The present study reveals a universe around the nurses which was almost not explored in the context of the history of nursing, especially with regard to this history in Minas Gerais, particularly the capital city Belo Horizonte.
\end{abstract}

Keywords: nursing; history of nursing; public health; Belo Horizonte.

\title{
Introdução
}

Apesar de ser inaugurada em 1897 sem que contasse com único hospital, a cidade de Belo Horizonte assistiu em suas primeiras décadas à organização do seu setor de saúde, com a criação de hospitais e da faculdade de medicina e a estruturação de alguns serviços de saúde pública pelo Estado. Dentre os grupos profissionais que se destacaram no período, privilegiaremos a enfermagem, primeiro como saber prático e depois como fruto de uma preparação realizada por meio de cursos rápidos, visto que a primeira escola de enfermagem, organizada segundo os modernos parâmetros profissionais e científicos - a Escola de Enfermagem Carlos Chagas -, somente seria criada em 1933.

O presente texto pretende analisar a atuação dos enfermeiros em Belo Horizonte nas ações voltadas à saúde pública, direcionadas inicialmente à prevenção e controle das doenças, com o combate e controle de epidemias e endemias, e, em seguida, à promoção da saúde, com a higiene e educação sanitária da população. Para a compreensão da inserção e atuação dos enfermeiros no período destacado, é importante entender em linhas gerais o ordenamento do serviço sanitário em Minas Gerais e em Belo Horizonte. 
A organização do serviço sanitário em Minas Gerais ganhou destaque no final do século XIX, com a reformulação da estrutura administrativa instituída pelo regime republicano, quando foram criados alguns órgãos e instituições para gerir a saúde e regulamentar as ações na área (MINAS GERAES, 1895a). Apesar desse esforço de organização administrativa instituída nos primeiros anos da República, os serviços de saúde ainda estavam pouco estruturados, além de se verificar a ocorrência de muitas epidemias. Nesse contexto, médicos higienistas receberam incentivos do governo, passando a ocupar cargos na administração pública, com o compromisso de estabelecer estratégias para o saneamento do país, trazendo recursos para a saúde pública (BERTOLLI FILHO, 1996).

O Regulamento Sanitário aprovado em 1895 atribuiu à Secretaria do Interior a responsabilidade pelas ações de saúde pública em todo o território mineiro. O serviço sanitário passava a ser composto pelo Conselho de Saúde Pública, órgão consultivo do governo nas questões relacionadas à higiene e salubridade; pela Diretoria de Higiene, encarregada da execução do regulamento sanitário; pelas Delegacias de Higiene e de Vacinação, subordinadas à Diretoria de Higiene e responsáveis pelas ações de saúde nos municípios, e pelos engenheiros, comissários de higiene e desinfectadores contratados pelo governo para as atividades do serviço sanitário, como o preparo e instalação de hospitais, montagem de aparelhos de desinfecção, execução de obras de saneamento e desinfecção de ambientes públicos e privados nos casos de epidemias (MINAS GERAES, 1895b).

Para a realização dessas atividades, a Diretoria de Higiene contava com uma equipe de trabalho permanente, além de pessoal contratado para desempenho das atividades conforme a necessidade sanitária do estado. Quanto ao pessoal destinado ao trabalho nesses locais, a única determinação era que fossem contratadas pessoas consideradas "idôneas e disciplinadas", que desempenhassem suas atividades seguindo os princípios de higiene então preconizados (MINAS GERAES, 1895c).

De acordo com a legislação, podemos dizer que o serviço sanitário estava organizado em torno da doença, fazendo-se necessária a criação de estabelecimentos responsáveis pelo combate e controle das moléstias infectocontagiosas, epidêmicas e endêmicas, cujas ações eram voltadas à desinfecção, à fiscalização e ao isolamento das pessoas infectadas. A doença foi também o motor para a contratação de parte do pessoal destinado ao trabalho nesses estabelecimentos, visto serem frequentemente requisitados em momentos de epidemias, ou na vigência de alguma situação anormal no estado - como, veremos, foi o caso dos enfermeiros.

No que diz respeito a Belo Horizonte, no ano de 1900 foi criada uma Seção de Higiene de âmbito municipal. Esta seção era composta pelo médico da 
prefeitura, por um escriturário, um fiscal de assistência pública e pelo pessoal subalterno necessário ao desenvolvimento das atividades sanitárias, podendo o prefeito nomear médicos auxiliares e mais pessoal subalterno se a situação do município assim o exigisse (MINAS GERAES, 1900). Como comenta Silveira (2007) em relação à higiene na cidade de Belo Horizonte, desde a escolha do lugar para a construção da capital, assim como ao longo do processo de sua construção, essa se manteve como problema que deveria ser administrado de perto pelas autoridades.

Nessa ordem de preocupações, o então presidente do estado, Silviano Brandão, nomeou Cícero Ferreira para o posto médico da capital. Cícero Ferreira assumiu a Seção de Higiene e Assistência Pública da prefeitura no ano de 1900, órgão responsável pelas questões referentes à salubridade e higiene na capital (SILVEIRA, 2007). Como continua a autora, essas ações, além da ausência de moléstias epidêmicas e contagiosas que grassavam em outras regiões, contribuíram para compor um discurso sobre a salubridade da capital mineira, construída conforme os preceitos da engenharia sanitária estabelecidos na segunda metade do século XIX.

Ressalta-se que, apesar das medidas preventivas e da preocupação do governo em manter a cidade longe dos surtos e das epidemias, ações pontuais e voltadas principalmente para Belo Horizonte não resolviam os problemas de saúde pública que poderiam se abater sobre o estado. Nesse sentido, era preciso reorganizar esse serviço, no que diz respeito ao âmbito estadual, com instituições e profissionais voltados a esse fim, procurando-se minimizar os transtornos causados pelas afecções infectocontagiosas e melhorar o tratamento dispensado aos doentes, o que foi ocorrendo ao longo das décadas de 1910 e 1920.

Nas palavras de Ribeiro (1993), a ênfase da organização da saúde pública no início do século XX no Brasil foi para o controle médico sobre a população, a casa, a água, o esgoto, a ventilação e o lixo, tornando esses profissionais os organizadores e administradores do espaço coletivo. E, em nosso entendimento, foram esses médicos que também determinaram o controle e as ações dos enfermeiros que atuavam na saúde pública à época.

Mudanças mais profundas na forma de condução da saúde pública no Brasil ocorreram principalmente a partir da década de 1920. Segundo Lima e Hochman (1998), 1920 marcou o início da nacionalização das políticas de saúde e saneamento e a definição de uma nova identidade profissional para um grupo de médicos, como profissionais de saúde pública, vinculados à administração pública e com especialização e organização distintas dos demais. Nesse período, a ênfase campanhista e de combate às epidemias sofreu alteração, tendo por foco um projeto de educação sanitária, no sentido de promover e proteger a saúde da população e não apenas combater a doença. Esse foi o cenário, tam- 
bém, para a atuação da enfermeira visitadora, que passou a ser requisitada para o trabalho na área, como uma oferta mais especializada entre os enfermeiros, como veremos em seguida.

\section{Enfermeiros na saúde pública}

Inicialmente, nossa discussão sobre a inserção dos enfermeiros na saúde pública gira em torno da atuação formal e informal destes, desde o final do século XIX até o final da década de 1910, momento em que as ações de saúde pública estavam voltadas ao combate dos surtos e epidemias, tendo no saneamento das cidades uma grande preocupação. No segundo momento, compreendido entre a década de 1920 e início da década de 1930, a atuação dos enfermeiros passou a privilegiar as ações de saúde pública com vistas à educação sanitária, à preocupação com o indivíduo, requerendo para atuação nessa área pessoas com um treinamento mais específico.

Em fins do século XIX e início do XX, em Minas Gerais e em Belo Horizonte, foi possível constatar a presença de enfermeiros atuando no combate e controle das doenças. Nesse sentido, havia o enfermeiro que trabalhava na saúde pública, contratado pelo governo, mesmo que temporariamente, para desempenhar atividades em instituições públicas, como hospitais de isolamento, ou nas visitas e no trabalho nos lares dos doentes, realizando ações de higiene e cuidado que lhes fossem determinadas e com acompanhamento da equipe médica. Essas atividades remetem à atuação formal do enfermeiro, que realizava um trabalho com atribuições e responsabilidades, mediante contrato de trabalho, recebendo honorários. A atuação formal também remete, em alguns momentos, às atividades voluntárias de enfermagem em épocas de surtos e epidemias, mas, de qualquer forma, inseridas em um contexto de dominação da medicina, que determinava aos enfermeiros o que poderia e deveria ser realizado.

Simultaneamente à atuação formal, identificamos a informal: nesse caso, a pessoa que exercia ajuda a um doente era chamada de enfermeiro, independente de contrato de trabalho e de salário, realizando a atividade de enfermagem de modo informal. Normalmente, eram vizinhas, conhecidas ou amigas dos doentes e se dispunham a ajudá-los nos momentos de enfermidade ou incapacidade. Nessa época, quando as pessoas adoeciam, outras se colocavam à disposição para ajudar, realizando atividades de apoio, assistência e cuidado que tinham um caráter de informalidade e envolviam mais um apelo caritativo. Estabelecia-se uma rede de relações entre os mais próximos e também entre aqueles que tinham um pouco de "conhecimento" sobre o modo de cuidar e tratar uma doença. 
Porém, à medida que a medicina buscava sua consolidação e o domínio de um campo do saber, essa prática passou a ser condenada e combatida, no sentido de que o tratamento e a forma de cuidado deveriam partir da indicação e do acompanhamento médico. Como discute Pereira Neto (2001), os médicos, nas primeiras décadas do século XX, buscavam delimitar o seu espaço e isso implicou ter o controle das atividades e das outras profissões de saúde, ao mesmo tempo em que se valiam destas para que seu trabalho fosse realizado com êxito.

Em estudo sobre a profissionalização da medicina e os processos-crime ocorridos na capital mineira entre o final do século XIX e a década de 1920, Oliveira (2008) menciona que, a partir da última década do século XIX, os médicos ganharam mais respaldo legal para obter o monopólio das artes de curar. Segundo a autora, com a profissionalização, os médicos buscaram restringir o campo de seu exercício profissional, desacreditando e desautorizando as terapias não credenciadas pela ciência médica acadêmica e definindo espaços e ações entre os agentes responsáveis pelo atendimento ao doente. Nesse sentido, podemos dizer que, ao mesmo tempo em que a medicina procurava consolidar-se como profissão, eliminando aqueles que não seguiam os padrões oficiais para o seu exercício, ela também procurava organizar o espaço de atuação desses outros agentes envolvidos na assistência ao doente, estabelecendo e delimitando suas competências. Então, ao mesmo tempo em que reordena e reorganiza o espaço de cura, a medicina interfere e gera demandas de organização dessas outras ocupações e atividades com ele envolvidas.

Na capital mineira, Cícero Ferreira, diretor da Seção de Higiene e Assistência Pública da prefeitura de Belo Horizonte, procurava ressaltar a atuação formal dos enfermeiros, dando ênfase às características consideradas desejáveis entre essas pessoas, qualificando-as e afirmando a importância do trabalho das mesmas para a conquista de um bem maior - qual seja, a não propagação de uma determinada doença (FERREIRA, 1907). Para isso, era preciso ter ao lado dos médicos uma pessoa hábil, com aptidão ou capacidade para desenvolver as atividades de cuidado, ao mesmo tempo solícita, prestativa e também cuidadosa, que agisse com atenção e desvelo ${ }^{2}$. A esse enfermeiro poderia ser entregue mais de um doente, pois ele sabia o que deveria ser feito e "dava conta do recado", inspirando a confiança dos médicos. Esses, ao que sugere o texto, tinham o controle sobre a doença, sobre sua propagação, sobre a forma de prestar assistência aos doentes e as providências a serem tomadas com o restante da população - o que não acontecia quando os cuidados eram realizados apenas como uma forma de ajuda e pelo sentimento humanitário.

2 Os destaques, em itálico, indicam palavras que foram utilizadas por Cícero Ferreira em relatório sobre a epidemia de varíola em Belo Horizonte. Cf. Ferreira (1907). 
Podemos dizer que os médicos precisavam dos enfermeiros para que seu trabalho fosse realizado com sucesso, devendo estes acompanhá-los às visitas e executar o que fosse determinado para evitar que o "mal nascente" (ou seja, a doença) fosse propagado. Mas os médicos não poderiam ser acompanhados por qualquer pessoa. Era preciso ser um "excelente enfermeiro" (FERREIRA, 1907), pois essa qualidade significava uma pessoa competente no desempenho de suas atividades e, provavelmente, idônea e disciplinada, que seguia as instruções e ajudava o médico no que fosse necessário para combater a doença junto à população, atuando, também, em instituições destinadas à observação e ao tratamento dos doentes.

Os enfermeiros eram contratados para prestar seus serviços em momentos de ameaça, em que havia a necessidade de controle e combate às doenças epidêmicas, como estava estabelecido na legislação do serviço sanitário do estado, tanto de 1895, como de 1910. Em tempos "anormais", devia-se contratar o pessoal idôneo e disciplinado necessário para o combate de epidemias (MINAS GERAES, 1895c, 1910), o que se constituía em uma característica das ações de saúde desde o período imperial: ser reativa e não preventiva, buscando meios de ação e recursos materiais e humanos a partir de um problema instalado (SILVEIRA; FIGUEIREDO, 2011).

Em relação aos locais de atuação do enfermeiro, a documentação nos permitiu identificar: as hospedarias de imigrantes e os hospitais de isolamento do estado. Nesses locais as atividades desempenhadas pelo enfermeiro relacionavam-se de forma mais específica à organização de alguns dos serviços da instituição, às medidas de higiene, à observação e atenção aos doentes, como a administração de medicamentos e dietas (MINAS GERAES, 1898).

Já a década de 1920 marcou um novo dimensionamento da questão sanitária, com avanços em termos da medicina preventiva e da saúde pública. A ênfase das ações de saúde voltou-se para a educação e prevenção da doença, com a diversidade e ampliação dos serviços de atendimento à população, que passaram a ter um caráter permanente, como os centros de saúde e postos de higiene. Essa ampliação decorreu do contrato firmado entre a Diretoria de Higiene e a Fundação Rockefeller, em 1918, conforme nos esclarece o diretor de Higiene, Ernani Agricola (1930, p. 19):

Os centros de saúde e postos de hygiene são unidades sanitárias que correspondem satisfatoriamente às necessidades modernas para o desenvolvimento e aperfeiçoamento dos trabalhos de saude publica. Estas instituições surgiram em nosso meio, graças ao contacto de nossos hygienistas com os methodos norte-americanos sobre questões sanitárias. 
Pelos acordos firmados, seriam criados os Serviços Permanentes de Higiene pelos municípios e caberia à Fundação Rockefeller contribuir financeiramente e com profissionais experimentados (LIBÂNIO, 1922, p. 7). Aos centros de saúde caberia a educação sanitária da população em geral e a execução dos serviços de assistência sanitária e os relativos à higiene pré-natal e infantil, pré-escolar e escolar, verminoses, tuberculose, sífilis, doenças venéreas, tracoma, paludismo, nutrição e dietética, higiene do trabalho e higiene mental (AGRICOLA, 1930). Com a prevenção ganhando importância frente à assistência ao doente, as ações do enfermeiro de saúde pública são ampliadas, exigindo um agente mais qualificado em relação aos enfermeiros que atuavam nos períodos anteriores. Em nosso entendimento, esse período pode ser considerado um "divisor de águas" para a enfermagem, trazendo à luz um novo personagem, no caso a mulher enfermeira, que passou a representar a categoria a partir daquele momento, e ampliando consideravelmente o espaço de atuação desses profissionais, que passaram a atuar também em dispensários, centros de saúde, postos de higiene e nas visitas domiciliares, voltadas, principalmente, para a educação sanitária.

Nas palavras de Santos e Faria (2008, p. 35), “[...] a década de 1920 instaurou novas práticas e concepções na relação Estado e sociedade, acentuando-se a especialização em saúde pública ou higiene. A formação de novas categorias seguiu um modelo de profissionalização baseada na 'feminização' da atenção ao paciente e às famílias", destacando-se, nesse contexto, as educadoras sanitárias e as enfermeiras.

Na primeira metade da década de 1920, o serviço de higiene municipal de Belo Horizonte já contava com o dispensário e um posto de profilaxia para doenças transmissíveis e a inspeção médica nas escolas dava os primeiros passos para a sua organização. Nesses locais, sobressai a presença de enfermeiras e as atividades por elas realizadas no âmbito da saúde pública, como revela a mensagem do presidente Arthur Bernardes (1922, p. 52) ao Congresso Mineiro:

Em Belo Horizonte foi installado um Posto Central de Prophylaxia das Doenças Venereas e que vae tendo perfeito êxito, sobretudo do ponto de vista social, já conseguindo o affluxo espontâneo ou a convite da enfermeira visitadora, do meretrício contaminado e contaminador [...].

Por meio desse relato, fica evidenciada a realização da visita sanitária como parte das atribuições da enfermeira, denominada "enfermeira visitadora". Nesse caso, ela era o elo entre a população, o posto e a medicina, fazendo a identificação e captando as pessoas doentes para que recebessem tratamento e 
fossem orientadas em relação à transmissão de doenças. No trabalho de visitação, cabia à enfermeira ganhar a confiança dos envolvidos, o que, como relatado na mensagem do presidente, estava produzindo êxito, ainda mais em se tratando de doenças venéreas.

A enfermeira visitadora também atuava no dispensário criado na capital. Em relação às visitas realizadas no ano de 1925, o presidente do estado, Fernando Mello Vianna (1925, p. 174), informou que "[...] foram feitas no Dispensário Central 2700 visitas pela enfermeira visitadora e 229 pelo médico". O número de visitas realizadas mostra que essa atividade era árdua e de muita responsabilidade, uma vez que dela dependia a identificação de doenças, a vigilância dos casos e o afluxo de pessoas ao dispensário. Para a realização dessas atividades, a enfermeira deveria ter conhecimento das formas de transmissão das doenças, de pelo menos alguns sintomas e das medidas profiláticas, sendo requerido dela conhecimento maior para que pudesse atuar. Cabe ressaltar que, quando da visita, a enfermeira era a "autoridade", uma vez que não estava acompanhada dos médicos e tinha que decidir sobre a situação apresentada. Nesse sentido, como indica Davies (1983), a saúde pública possibilitou às enfermeiras a conquista de certa autonomia e de legitimidade diante da hierarquia médica, o que foi se conformando mesmo antes da profissionalização. Ainda que o limite de suas funções fosse determinado pelos doutores, à medida que realizavam as visitas, as enfermeiras iam também sendo reconhecidas, conquistando um espaço próprio.

No que se refere às enfermeiras visitadoras que prestavam seus serviços na saúde pública em Belo Horizonte no início da década de 1920, não foram encontrados documentos que fizessem menção ao preparo ou à forma de entrada dessas mulheres para o trabalho em saúde, mas é provável que tivessem que frequentar alguns cursos, como foi relatado no caso do Rio de Janeiro (FRAENKEL, 1934).

No caso de Belo Horizonte, destacamos que, à medida que novos serviços de atenção à saúde eram criados, a demanda por novos agentes de saúde pública crescia, o que fez com que as chamadas enfermeiras escolares surgissem nesse cenário. Em fins da década de 1910, autoridades governamentais discutiam a efetiva inserção da inspeção médica nas escolas, no sentido de contribuir para a profilaxia de doenças, para o saneamento e as melhorias dos edifícios escolares, bem como para o desenvolvimento físico e intelectual dos alunos (BERNARDES, 1919). A inspeção médica escolar, segundo Vareto (2010), foi oficialmente instituída pela Reforma Educacional Mello Vianna, no ano de 1925, a partir da qual os grupos escolares, progressivamente, foram contemplados pela assistência médica e odontológica. Inicialmente, o trabalho envolvia apenas assistência médica e, no primeiro ano de instalação desse serviço, os atendimentos tiveram pouca abrangência e eficácia, limitando-se à pesagem e medição das crianças, 
ao exame da acuidade auditiva e visual dos alunos e ao controle de verminoses. Nesse contexto, o presidente Fernando de Mello Vianna (1926, p. 128) proferiu a seguinte mensagem:

[...] Nessa ordem de considerações, em face do elevado numero de alumnos das nossas escolas primarias, fui levado á creação de um corpo de enfermeiras escolares, convenientemente habilitadas para o fim a que se destinam, tendo cada uma sob sua directa fiscalização sanitária cerca de 600 alumnos.

Terá a enfermeira como principais funç̧ões: incutir no alumno hábitos de hygiene e fiscalizal-o na pratica dos mesmos; surprehender no seu estado inicial as moléstias contagiosas escolares, tomando as medidas prophylacticas convenientes; encher, na parte que lhe competir a ficha sanitaria individual dos alumnos, apresentar ao médico escolar, por ocasião da visita deste, os alumnos que durante a semana se mostraram doentes ou por qualquer fórma suspeitos; ir, todas as vezes que necessario, e devidamente instruídas pelo medico escolar, á casa do alumno não só para indagar dos seus hábitos de asseio, como para levar recomendações hygienicas especiais aos respectivos paes; proceder ás pesagens e medidas anthropometricas periodicas dos alumnos; distribuir alimentos aos alumnos necessitados; fazer o serviço estatístico de acordo com as instruções do medico escolar, etc.

Percebemos a crescente complexificação das atividades das enfermeiras, com desempenho de funções relacionadas, de modo geral, à prevenção e controle de doenças, à identificação e vigilância dos casos, ao preenchimento das fichas de saúde e à promoção da saúde, principalmente, com a educação sanitária, e à exigência de uma habilitação para o desempenho das atividades para com os escolares. A qualificação da enfermeira como "visitadora" já não era o eixo em torno do qual ela devia realizar suas ações. A visitação continuava a fazer parte de suas atividades, mas agora era preciso tornar-se "escolar", ou melhor, “especializada" nessa área. Nesse sentido, continua Vianna (1926, p. 129):

Para preenchimento dos logares de enfermeiros foi realizado um rigoroso concurso, tendo sido nomeadas as candidatas que melhores condições apresentaram relativamente á aptidão physica, intelligencia, instruç̧ão e educação. Feitas as nomeações, passaram as enfermeiras a freqüentar indispensável curso de adaptação, que ora se realiza sob direção do médico escolar da Capital. 
Pela primeira vez, encontramos referência a uma forma de contratação de enfermeiras nesse período, sendo delas exigida a aprovação em rigoroso concurso, para, em seguida, receber orientações que pudessem adaptá-las ao serviço escolar. Como na capital mineira não existia ainda formação profissional, foi organizado um curso pelo médico escolar contratado pelo governo a fim de que as enfermeiras se especializassem na qualidade de enfermeiras escolares, como era então sugerido pelas autoridades do Departamento Nacional de Saúde Pública.

A referência ao preparo de enfermeiras foi ressaltada em outras mensagens de presidentes de Minas Gerais, indicando uma preocupação dos governantes em acompanhar o que estava acontecendo na capital federal, onde a enfermagem profissional dava os seus primeiros passos. Se ainda não era possível em Minas, mais especificamente em Belo Horizonte, ter um corpo de enfermeiras diplomadas, elas deviam ao menos ser preparadas através de cursos rápidos e constantes instruções. O próprio regulamento do ensino primário, promulgado em 1927 (MINAS GERAES, 1927a, p. 1182), enfatizou a necessidade de a enfermeira "[...] procurar adquirir o conhecimento mais completo dos modernos pontos de vista sobre educação sanitária", para, assim, assistir aos professores com sua opinião e conselhos, auxiliá-los na inspeção de saúde, auxiliar o médico nos exames das crianças e induzir os pais, na visita domiciliar, a prover a saúde dos filhos.

Uma importante função das enfermeiras e dos médicos relacionava-se à criação e organização dos Pelotões de Saúde, voltados para promover a educação higiênica das crianças, incutindo e fixando hábitos saudáveis entre essas e tornando-as disseminadoras dos mesmos. Essas organizações, nas palavras de Piedade Filho (2009), auxiliavam na manutenção da higiene dentro das escolas, tendo em vista o asseio pessoal dos alunos e a prevenção de doenças. Sá (1925) recomendava a formação de pequenos grupos de escolares com mesma idade, sexo e condição social, para os quais seriam distribuídas as funções diárias de higiene e saúde a serem executadas pelos alunos membros do pelotão. O cumprimento fiel das obrigações implicava promoções, como uma forma de incentivar os alunos a realizarem as ações propostas. Segundo Vareto (2010), o pelotão estava presente em quase todos os grupos escolares de Minas Gerias, organizando eventos, teatros, projetos manuais a partir do tema da higiene.

Podemos dizer que as enfermeiras acompanhavam regularmente as crianças, realizando atividades de educação higiênica, com ensino de hábitos de higiene aos alunos e sua fiscalização. Nas palavras de Rocha (2003), as práticas escolares de educação higiênica foram uma obra de "modelagem" e disciplinamento da infância para aquilo que era considerado adequado em termos de saúde, devendo as crianças vivenciá-las cotidianamente. Dentre essas, a autora destaca a revista do asseio do corpo e das roupas e a revista da escola 
pelos alunos, num exercício que os aproximava das práticas desenvolvidas pelos inspetores sanitários e que os faria desenvolver a capacidade de vigilância sobre o ambiente doméstico. As práticas de educação higiênica também envolviam a observação e correção das condutas contrárias aos preceitos de higiene; as mensurações de peso, altura e força física; e a investigação, como ressalta a autora, discreta e hábil sobre a vida doméstica do aluno, que serviria de orientação para a condução das propostas de higiene. Essas práticas tinham um poder educativo que não se reduzia ao âmbito da escola, “[...] na medida em que procuravam atingir as crianças e suas famílias, ensinando-lhes um modo de vida civilizado e purificando-lhes das condenáveis práticas que, nas representações dos médicos-higienistas, caracterizavam o seu cotidiano" (ROCHA, 2003, p. 48).

No sentido de abarcar as práticas de educação sanitária em diversos aspectos, o regulamento do ensino primário de Minas Gerais também previa a atuação de enfermeiras, nas escolas, como assistentes dos dentistas, sendo essas denominadas enfermeiras assistentes. Suas funções eram definidas como:

Inspeccionar semanalmente ou quando julgar necessário a bocca das creanças e verificar si são cumpridas as recommendações do dentista e as suas;

encaminhar os alunnos ao dispensário quando for necessária a assistência technica;

ministrar ás creanças instrucções individuaes dos preceitos de hygiene; assistir ás professoras, na sua funcção de ensinar educação hygienica, com os seus conselhos e instrucções.

fazer a limpeza do apparelho dentário das creanças e o expurgo da bocca; praticar os curativos de urgência;

fazer as visitas domicialiares nos casos indicados;

manter em ordem o archivo e o arranjo da clinica, assistindo ao seu funccionamento (MINAS GERAES, 1927a, p. 1186).

Nesse sentido, as atividades das enfermeiras eram voltadas, primordialmente, à educação e higiene. Para que as ações propostas fossem efetivadas, era importante a vigilância contínua, com inspeção dos alunos, orientação de professores e pais, no sentido de criar uma "consciência sanitária". A legislação do ensino preconizava, para enfermeiras assistentes, a realização de um treinamento específico, podendo o Estado entrar em acordo com a Escola de Odontologia da Universidade de Minas Gerais para a criação de um curso destinado à formação das mesmas (MINAS GERAES, 1927a). 
O trabalho das enfermeiras escolares, em Belo Horizonte e, provavelmente, das enfermeiras assistentes, parece ter sido centralizado nos dispensários escolares, com a criação dos mesmos a partir do final da década de 1920. Esses locais eram equipados com gabinetes médicos e dentários para assistência aos alunos, cujas ações envolviam o auxílio das enfermeiras.

A necessidade de formação e melhor preparo das enfermeiras para o trabalho em saúde pública foi enfatizada em vários momentos, o que indica uma diferenciação em relação aos períodos anteriores em Minas e em Belo Horizonte, quando essa preocupação não foi ponto de destaque. Em nosso entendimento, no primeiro momento o que estava em jogo eram ações basicamente de controle da disseminação de uma doença e, para isso, bastava que os enfermeiros seguissem os parâmetros de desinfecção e isolamento estabelecidos pelos médicos, sem a preocupação efetiva com o indivíduo e a coletividade, no sentido de promover e preservar a saúde, como foi a tônica a partir da década de 1920. Para esse caso, era preciso que os enfermeiros tivessem um conhecimento e preparo maior, uma vez que seriam responsáveis pela educação e vigilância sanitária, atuando diretamente com a população e convocando-a a aderir novos valores.

Além do trabalho nos dispensários escolares, a proposta dos Centros de Saúde e Postos de Higiene começou a se concretizar em Belo Horizonte na passagem entre as décadas de 1920-1930. Nesses locais, a ênfase do trabalho em saúde pública voltava-se para a educação em saúde, cujas ações de médicos e enfermeiras faziam-se importantes para o contato e "convencimento" da população de modo geral. Nesse sentido, Andrada (1930, p. 149-150) relata algumas das ações realizadas:

A educação sanitaria do povo, por meio de conferencias, palestras, cartazes, artigos e notas na imprensa, filmes, projecções, teve largo incremento, distribuindo-se 715.752 impressos e realizando-se 124 conferencias e milhares de palestras, pelos medicos, enfermeiras e fiscaes dos Centros e Postos de Hygiene.

Procurou-se, em cada municipio dotado de organisação sanitaria, intensificar a propaganda e educação hygienica de modo a preparar o publico para receber as medidas que fossem exigidas a bem da collectividade e instruil-o nos methodos de conservar a saude e evitar doenças. [...] As enfermeiras visitadoras, na sua alta funcção de instruir o publico e encaminhar os contagiantes para os ambulatórios, realizaram no anno findo 67.886 visitas domiciliares.

Por meio desse relato, ficam evidenciadas as ações de educação sanitária 
realizadas por médicos e enfermeiras, de modo a preparar o público para receber as medidas de higiene e instruí-lo quanto à melhor maneira de conservar sua saúde, sendo utilizados recursos como impressos, filmes, projeções e palestras para esse fim. Além dessas atividades, a visita domiciliar continuou a fazer parte das atribuições das enfermeiras, com o objetivo de instruir a população e detectar os casos de doenças. Como preconizava a legislação da saúde pública em Minas Gerais à época, era importante, nas visitas domiciliares, que as enfermeiras realizassem a vigilância sanitária em casos de doenças transmissíveis, como as doenças venéreas e a tuberculose, esforçando-se para que os doentes levassem a termo o tratamento e os meios para evitar o contágio. Outro aspecto do trabalho das enfermeiras na saúde pública estava relacionado com o auxílio aos médicos, na higiene pré-natal e infantil, promovendo a vinda de mulheres grávidas, mães e crianças sadias aos postos de atendimento, ensinando-lhes regras de alimentação, vestuário e asseio corporal (MINAS GERAES, 1927b).

Podemos então dizer que o bom funcionamento dos serviços de saúde e a adesão do público às propostas preconizadas dependiam, em grande medida, da atuação das enfermeiras. Como relatam Santos e Faria (2008), a atuação das enfermeiras foi se consagrando como imprescindível nas atividades de prevenção. Nas palavras de Deslandes et al. (2013, t. 4),

[...] ao serem enviadas aos domicílios, a fim de educar as famílias e praticar ações voltadas para a promoção da saúde, relacionadas ao repouso, à boa alimentação e ao ambiente arejado, as enfermeiras reproduziam o cuidado como uma das estratégias para a credibilidade da Reforma Sanitária.

Contudo, além da proposta principal de educação em saúde, o Estado não poderia se descuidar das doenças infectocontagiosas que, porventura, pudessem atingir a população. Nesse sentido, o Regulamento de Saúde Pública de Minas Gerais previa a criação de um hospital de isolamento na capital mineira, o Hospital Cícero Ferreira, destinado à observação, isolamento e tratamento de indivíduos acometidos por essas doenças (MINAS GERAES, 1927b). Era preconizada a existência do enfermeiro-chefe e de enfermeiras. O enfermeiro-chefe deveria residir no hospital, zelando por sua ordem interna. A ele cabia cuidar da conservação do material, do asseio e da disciplina dos funcionários; fiscalizar a aplicação terapêutica instituída pelo médico e a distribuição de dietas; acompanhar os médicos em sua visita; organizar o serviço burocrático das enfermarias; tomar as providências cabíveis quando do falecimento de um doente, e dirigir e fiscalizar os processos de desinfecção e os serviços das 
enfermarias, lavanderias, cozinha e demais seções, ministrando as instruções necessárias. Aos enfermeiros subordinados cabia cumprir as ordens de serviço do diretor do hospital e do enfermeiro-chefe; dispensar cuidados aos doentes, e fazer o controle da rouparia e da despensa (MINAS GERAES, 1927b). Sobre esse hospital, não foi encontrada nenhuma outra documentação que nos dissesse a respeito do seu funcionamento e do cotidiano dos enfermeiros nesse local.

Nesse contexto de atuação dos enfermeiros na saúde pública, podemos dizer que foi no âmbito da educação sanitária que as atividades de enfermagem ganharam em complexidade e autonomia e colocaram em destaque a mulher enfermeira como importante agente de saúde e elo entre o governo, a medicina e a população. Como indica Moreira (1999, p. 641), “[...] numa conjuntura histórica específica, a enfermagem veio responder às demandas do Estado, aumentando a ingerência da saúde pública na organização das cidades, dos espaços e dos cidadãos." Apropriando-nos aqui das palavras de Perrot (2005), a mulher, "saindo" do espaço doméstico para o público, inicialmente fez da caridade um dos meios para realizar atividades neste espaço e, em seguida, lançou-se na empreitada de moralização e de higiene, sabendo se apropriar dos espaços que lhes foram deixados ou confiados.

\section{Considerações finais}

A atuação de enfermeiros na saúde pública foi direcionada pelo pensamento sanitário da época, em que prevaleceram, nas duas primeiras décadas do século XX, as ações em torno da doença e, na década de 1920, em torno da saúde. Nesse contexto, de um enfermeiro cuja atuação estava voltada ao trabalho de desinfecção e isolamento dos doentes, contratado para prestar serviços temporários e sem uma demanda de qualificação, passamos a ter uma enfermeira voltada ao trabalho de educação e vigilância, de forma contínua e com maior qualificação na prestação da assistência requerida, tudo isso antes da afirmação do ensino regular de enfermagem em Belo Horizonte.

De modo geral, o presente estudo revela um universo em torno dos enfermeiros ainda pouco trabalhado no contexto da história da enfermagem, principalmente, no que diz respeito a essa história em Minas Gerais, com destaque à capital Belo Horizonte. Desse modo, esperamos contribuir para as discussões relacionadas ao tema e sinalizar aspectos da enfermagem exercidos no período que antecede a criação das escolas, marcado pela organização em torno da prática e a necessidade de propagar os preceitos da higiene. 


\section{REFERÊNCIAS}

AGRICOLA, E. Centros de Saúde e Postos de Hygiene no Estado de Minas Geraes. In: CONGRESSO BRASILEIRO DE HYGIENE, 5., 1929, Recife. Annaes... Sessoes Plenarias. Rio de Janeiro: Officinas Graficas da Inspectoria de Demographia Sanitaria, 1930, p. 19-35.

ANDRADA, A. C. R. Mensagem dirigida ao Congresso Mineiro. Bello Horizonte, 1930. (Mensagens dos Presidentes de Província). Disponível em: $<$ http://brazil.crl.edu/bsd/bsd/ u314/>. Acesso em: 10/8/2010.

BERNARDES, A. S. Mensagem dirigida ao Congresso Mineiro. Bello Horizonte, 1919. (Mensagens dos Presidentes de Província). Disponível em: $<\mathrm{http}: / / \mathrm{brazil.crl.edu/bsd/bsd/}$ u303>. Acesso em: 10/8/2010.

. Mensagem dirigida ao Congresso Mineiro. Bello Horizonte, 1922. (Mensagens dos Presidentes de Província). Disponível em: <http://brazil.crl.edu/bsd/bsd/u306>. Acesso em: 10/8/2010.

BERTOLli FILHO, C. História da saúde pública no Brasil. São Paulo: Ática, 1996.

DAVIES, C. Professionalizing strategies as time and culture bound: American and British nursing, circa 1893. In: LAGEMANN, E. C. (Ed.). Nursing History: new perspectives, new possibilities. New York and London: Teachers College, Columbia University, 1983. Cap. 3, p. 47-64.

DESLANDES, A. K. M. et al. A imagem do cuidado prestado pelas enfermeiras de saúde pública veiculada na Revista da Semana (1929). Rev. Latino-Am. Enfermagem, Ribeirão Preto, v. 21, n. 1, 07 telas, jan./fev. 2013.

FERREIRA, C. Providencias therapeuticas e prophylacticas postas em pratica durante a epidemia de varíola. Relatório apresentado ao Secretario do Interior. Belo Horizonte, 1907. (Arquivo Público Mineiro, Secretaria do Interior, 1703).

FRAENKEL, E. Histórico do Serviço de Enfermeiras do Departamento Nacional de Saúde Pública. Annaes de Enfermagem, Rio de Janeiro, v. 5, n. 5, p. 4-10, abr. 1934.

LIBÂNIO, S. Relatório apresentado ao Secretario do Interior. Bello Horizonte: Imprensa Official, 1922. (Arquivo Público Mineiro, Relatórios da Diretoria de Hygiene do Estado de Minas Gerais).

LIMA, N. T.; HOCHMAN, G. Condenado pela raça, absolvido pela medicina: o Brasil descoberto pelo movimento sanitarista da Primeira República. In: MAIO, M. C.; SANTOS, R. V. (Org.). Raça, ciência e sociedade. Rio de Janeiro: Fiocruz, 1998. p. 23-40.

MINAS GERAES. Decreto 1195 de 7 de outubro de 1898. Supprime os logares de ajudante do administrador, interpretes, fiel de armazem, enfermeira e um guarda da 
Hospedaria de Immigrantes de Juiz de Fora. Minas Geraes, Cidade de Minas, 9 out. 1898. (Imprensa Oficial do Estado de Minas Gerais).

. Lei n. 6 de 16 de outubro de 1891. In: COLLEÇÃO das Leis: confeccionadas pelo Congresso em sua primeira reunião em 1891. Ouro Preto: Imprensa Official do Estado de Minas Gerais, 1895a. (Arquivo Público Mineiro, Leis Mineiras).

. Lei n. 144 de 23 de julho de 1895. Organiza o serviço sanitário do estado. $M i$ nas Geraes, Ouro Preto, 28 jul. 1895b. (Imprensa Oficial do Estado de Minas Gerais).

. Leis Mineiras. Decreto 876 de 30 de outubro de 1895. Regulamenta a lei 144, de 23 de julho de 1895, que organiza o serviço sanitário. Ouro Preto, 1895c. (Assembleia Legislativa do Estado de Minas Gerais). Disponível em: <http://hera.almg.gov. br>. Acesso em: 27/7/2011.

. Leis Mineiras. Decreto 1358 de 6 de fevereiro de 1900. Approva o regulamento que crêa uma secção de hygiene na Prefeitura da Cidade de Minas. Cidade de Minas, 1900. (Assembleia Legislativa do Estado de Minas Gerais).

. Leis Mineiras. Decreto 2733 de 11 de janeiro de 1910. Regulamenta a lei n. 452, de 9 de outubro de 1906. Belo Horizonte, 1910. (Assembleia Legislativa do Estado de Minas Gerais).

. Leis Mineiras. Decreto 7970-A de 15 de outubro de 1927. Approva o Regulamento do Ensino Primario. Belo Horizonte, 1927a. (Assembleia Legislativa do Estado de Minas Gerais).

. Leis Mineiras. Decreto 8116 de 31 de dezembro de 1927. Approva o regulamento de Saúde Pública. Belo Horizonte, 1927b. (Assembleia Legislativa do Estado de Minas Gerais).

MOREIRA, M. C. N. A Fundação Rockefeller e a construção da identidade profissional de enfermagem no Brasil na Primeira República. História, Ciências, Saúde-Manguinhos, Rio de Janeiro, v. 5, n. 3, p. 621-645, 1999.

OLIVEIRA, G. D. Curar e remediar: profissionalização médica nos processos-crime da Capital Mineira (1897-1927). 179 f. Dissertação (Mestrado em História) - Faculdade de Filosofia e Ciências Humanas, Universidade Federal de Minas Gerais, Belo Horizonte, 2008.

PEREIRA NETO, A. F. Ser médico no Brasil: o presente no passado. Rio de Janeiro: Fiocruz, 2001.

PERROT, M. As mulheres ou os silêncios da história. Bauru: EDUSC, 2005.

PIEDADE FILHO, L. F. R. Asseados e valorosos: o Pelotão de Saúde Oswaldo Cruz e sua cruzada higienista. Temporalidades, Belo Horizonte, v. 1, n. 2, p. 65-84, ago./dez. 2009.

RIBEIRO, M. A. R. História sem fim... Inventário da saúde pública-São Paulo-18801930. São Paulo: UNESP, 1993. 
ROCHA, H. H. P. Educação escolar e higienização na infância. Cadernos Cedes, Campinas, n. 23, n. 59, p. 39-56, abr. 2003.

SÁ, C. A Educação Hygienica na Escola Primaria. Rio de Janeiro: DNSP/Canton e Beyer, 1925.

SANTOS, L. A. C.; FARIA, L. R. As ocupações supostamente subalternas: o exemplo da enfermagem brasileira. Saúde Soc., São Paulo, v. 17, n. 2, p. 35-44, 2008.

SILVEIRA, A. J. T. A Influenza Espanhola e a cidade planejada: Belo Horizonte, 1918. Belo Horizonte: Argumentum; FAPEMIG; CAPES, 2007.

SILVEIRA, A. J. T.; FIGUEIREDO, B. G. A saúde em Minas Gerais durante o século XIX. In: MARQUES, R. C.; SILVEIRA, A. J. T.; FIGUEIREDO, B. G. História da Saúde em Minas Gerais: Instituições e patrimônio arquitetônico (1808-1958). Barueri: Minha Editora, 2011.

VARETO, P. A. V. Intelectuais católicos, saúde e educação em Minas Gerais (19251930). 174 f. Dissertação (Mestrado em História das Ciências e da Saúde) - Casa de Oswaldo Cruz, Fundação Oswaldo Cruz, Rio de Janeiro, 2010.

VIANNA, F. M. Mensagem dirigida ao Congresso Mineiro. Bello Horizonte: Imprensa Official do Estado de Minas Geraes, 1925. (Mensagens dos Presidentes de Província). Disponível em: <http://brazil.crl.edu/bsd/bsd/u309/>. Acesso em: 9/1/2010.

. Mensagem dirigida ao Congresso Mineiro. Bello Horizonte: Imprensa Official do Estado de Minas Geraes, 1926. (Mensagens dos Presidentes de Província). Disponível em: <http://brazil.crl.edu/bsd/bsd/u310/>. Acesso em: 9/1/2010.

Texto recebido em 15 de outubro de 2014 . Texto aprovado em 21 de outubro de 2014. 